Our results were obtained with budesonide, and efficacy/safety profiles with different ICS treatments are drug and dose dependent. The meta-analysis of Sharek and Bergman, ${ }^{22} 10$ years ago, claimed that fluticasone slowed the growth less down than beclomethasone or budesonide. With increasing doses of fluticasone, the systemic effects may, however, seem quite significant. ${ }^{23}$ Ciclesonide seems to have little effect on growth. ${ }^{24}$ Nevertheless, our results accord the clinical experience. Most school-aged asthma children cope with intermittent ICS therapy, which also is favoured by parents and especially by those with corticosteroid fears.

Funding Helsinki University Hospital Research Grant (grant number: TYH2008302). Funder role: Academic support.

\section{Competing interests None.}

Patient consent Obtained.

Ethics approval Ethics approval was provided by Helsinki University Hospital Ethical Committee.

Contributors All authors have accepted to submit the paper to Thorax.

Provenance and peer review Not commissioned; externally peer reviewed.

Published Online First 28 October 2011

Thorax 2012;67:100-102.

doi:10.1136/thoraxjnl-2011-200246

\section{REFERENCES}

1. Childhood Asthma Management Program (CAMP) Research Group. Long-term effects of budesonide or nedocromil in children with asthma. N Engl J Med 2000;343:1054-63.
2. Pauwels RA, Pedersen S, Busse WW, et al. Early intervention with budesonide in mild persistent asthma: a randomized, double-blind trial. Lancet 2003;361:1071-6

3. Global Initiative for Asthma. Global Strategy for Asthma Management and Prevention. 2009. http:// www.ginasthma.com (accessed 21 Feb 2011).

4. Haahtela T, Tamminen K, Kava T, et al. Thirteen-year follow-up of early intervention with an inhaled corticosteroid in patients with asthma. J Allergy Clin Immunol 2009:124:1180-5.

5. Turpeinen M, Nikander K, Pelkonen A, et al. Daily versus as-needed inhaled corticosteroid for mild persistent asthma. The Helsinki Early Intervention Childhood Asthma Study. Arch Dis Child 2008;93:654-9.

6. Rytilä P, Pelkonen AS, Metso T, et al. Induced sputum in children with newly diagnosed mild asthma; the effect of 6 months of treatment with budesonide or disodium cromoglycate. Allergy 2004;59:839-44.

7. Balfour-Lynn L. Growth and childhood asthma. Arch Dis Child 1986;61:1049-55.

8. Price JF. Inhaled corticosteroids: clinical relevance of safety measures. Pediatr Pulmonol Suppl 1997:15:40-5.

9. Allen DB, Mullen M, Mullen B. A meta-analysis of the effect of oral and inhaled corticosteroids on growth. J Allergy Clin Immunol 1994;93:967-76.

10. Agertoft L, Pedersen S. Effect of long-term treatment with inhaled budesonide on adult height in children with asthma. N Engl J Med 2000;343:1064-9.

11. Nikander K, Turpeinen M, Pelkonen AS, et al. True adherence with the Turbuhaler in young children with asthma. Arch Dis Child 2011;96:168-73.

12. Turpeinen M, Pelkonen AS, Nikander K, et al. Bone mineral density in children treated with daily or periodical inhaled budesonide. The Helsinki Early Intervention Childhood Asthma (HEICA) study. Pediatr Res 2010:68:169-73.

13. Turpeinen M, Raitio H, Pelkonen AS, et al. Skin thickness in children treated with daily or periodical inhaled budesonide for mild persistent asthma. The Helsinki Early Intervention Childhood Asthma (HEICA) study. Pediatr Res 2010;67:221-5.

14. Pelkonen A, Kari 0, Selroos 0, et al. Ophthalmologic findings in children with asthma receiving inhaled budesonide. J Allergy Clin Immunol 2008;122:832-4

15. Boushey HA, Sorkness CA, King TS, et al. Daily versus as-needed corticosteroids for mild persistent asthma. N Engl J Med 2005;352:1519-28.

16. Papi A, Canonica GW, Maestrelli P, et al. Rescue use of beclomethasone and albuterol in a single inhaler for mild asthma. N Engl J Med 2007;356:2040-52.

17. Martinez FD, Chinchilli VM, Morgan WJ, et al. Use of beclomethasone dipropionate as rescue treatment for children with mild persistent asthma (TREXA): a randomised, double-blind, placebo-controlled trial. Lancet 2011;377:650-7.

18. Haahtela T, Tamminen K, Malmberg LP, et al. Formoterol as needed with or without budesonide in patients with intermittent asthma and raised NO levels in exhaled air: a SOMA study. Eur Respir $J$ 2006:28:748-55.

19. Bisgaard H, Szefler SJ. Understanding mild persistent asthma in children: the next frontier. J Allergy Clin Immunol 2005;115:708-13.

20. Naspitz CK, Cropp GJ. Recommendations for treatment of intermittent mild persistent asthma in children and adolescents. Pediatr Pulmonol 2009:44:205-8.

21. Allen DB. Inhaled steroids for children. Effects on growth, bone, and adrenal function. Endocrinol Metab Clin North Am 2005;34:555-64.

22. Sharek PJ, Bergman DA. The effect of inhaled steroids on the linear growth of children with asthma: a meta-analysis. Pediatrics 2000;106:E8.

23. Todd G. High-dose inhaled fluticasone, adrenal crisis and a fatal accident inquiry. Arch Dis Child 2007:92:372-3.

24. Skoner DP, Maspero J, Banerji D. Assessment of the long-term safety of inhaled ciclesonide on growth in children with asthma. Pediatrics 2008:121:e1-14.

\title{
Continuous versus intermittent inhaled corticosteroids for mild persistent asthma in children: not too much, not too little
}

\section{Francine M Ducharme $e^{1,2}$}

The goal of asthma treatment is to prevent exacerbations, achieve daily

\footnotetext{
'Department of Pediatrics, University of Montreal, Montreal, Quebec, Canada; ${ }^{2}$ Research Centre, CHU Sainte-Justine, Montreal, Quebec, Canada

Correspondence to Dr Francine M Ducharme, Professor, Department of Pediatrics, Associate Director of Clinical Research, Research Centre, CHU Sainte-Justine, 3175 Côte Ste-Catherine, Room 7939 Montreal, Quebec, H3T 1C5, Canada; francine.m.ducharme@umontreal.ca
}

asthma control and prevent adverse effects with a minimum of medication. In preschoolers, children and adolescents with mild persistent asthma, the most effective therapy remains daily use of low-dose inhaled corticosteroids. ${ }^{1}$ Why then consider intermittent therapy over maintenance inhaled corticosteroids?

The intermittent approach is attractive to patients and families for a variety of reasons, including fear of corticosteroid side effects, ${ }^{2}$ the erroneous concept that no symptoms equate to no disease ${ }^{3}$ and ease of compliance with medications administered for symptoms rather than on a daily basis. Indeed, pharmacy records clearly show that most children with asthma infrequently renew their prescriptions for controller medications, suggesting that they may not understand, perceive or agree with the need for daily therapy, despite ongoing healthcare resources utilisation and excess use of rescue $\beta 2$-agonist. ${ }^{4}$

This practice is also endorsed by physicians who recommend an asthma controller at the onset of an exacerbation for a short period. ${ }^{4}$ In vogue since the 1990s without, until recently, any supporting evidence, the practice of prescribing intermittent therapy over continuous therapy may have stemmed from: (1) the uncertain benefit of daily inhaled corticosteroids in patients in 
whom there is diagnostic uncertainty (viral wheeze vs asthma), phenotype hesitation (intermittent vs persistent) or a paucity of evidence for therapy (eg, preschoolers); (2) conflicting evidence regarding the long-term benefit of daily therapy as a disease modifier (eg, lung function, quality of life, airway remodelling $)^{6-8}$; (3) concerns about side effects of daily inhaled corticosteroids; and (4) in the absence of trials, unconvincing evidence of the harm or lack of efficacy of intermittent therapy. Admittedly, these factors may contribute to the 'giving-up to poor compliance' popular approach to avoid the time and energy required to repeatedly convince patients that the benefits of daily therapy outweigh possible harms. ${ }^{2} 910$ These reasons must be carefully addressed.

The scientific evaluation of intermittent controller therapy has started with adjustable single inhaler therapy in patients with persistent asthma receiving a daily combination of inhaled corticosteroids and fast long-acting $\beta 2$-agonists (ie, formoterol) in adults, ${ }^{11}{ }^{12}$ then in children. ${ }^{13}$ It extended to patients with intermittent asthma on no maintenance controller in whom placebo-controlled trials examined 'as-needed' combination therapy in adults ${ }^{14}$ and 'as-needed' inhaled corticosteroids ${ }^{15} 16$ or leukotriene receptor antagonists $^{17}$ monotherapy in children. The recent randomised control trials testing intermittent versus continuous controller monotherapy in adults ${ }^{18} 19$ and children $^{20}{ }^{21}$ with mild persistent asthma are the focus of this commentary.

In a 6-month, three-arm trial, Boushey et al evaluated as needed budesonide $(800 \mu \mathrm{g} /$ day for 10 days) in adults with mild persistent asthma who were taking $400 \mu \mathrm{g}$ daily budesonide or placebo; they observed no significant group difference in morning peak expiratory flow (PEF) rate and in exacerbations. ${ }^{18}$ However, maintenance monotherapy was clearly superior in improving forced expiratory volume in one second $\left(\mathrm{FEV}_{1}\right)$, airway hyper-reactivity, asthma control, symptom-free days and markers of eosinophilic inflammation. Intermittent budesonide was no different from daily zafirlukast and the authors appropriately emphasised the need for further studies before endorsement. ${ }^{18}$ In a 6-month, four-arm trial, Papi and colleagues evaluated daily $100 \mu \mathrm{g}$ of hydrofluoroalkane (HFA)-beclomethasone versus as needed two puffs of $50 \mu \mathrm{g}$ of HFA-beclomethasone dipropionate (BDP) and $100 \mu \mathrm{g}$ salbutamol combined in a single inhaler. There was no significant group difference in morning PEF, exacerbations, symptoms and rescue $\beta 2$-agonists use; thus, the authors concluded that both strategies were equivalent. ${ }^{19}$ The evidence in paediatrics is also limited to two trials, but several ongoing studies will shed more light on the topic in the near future (NCT00675584; NCT00394329). Turpeinen and colleagues designed an 18-month, 3-arm randomised controlled trial to carefully examine the efficacy and the safety profile of intermittent therapy in children with newly diagnosed asthma (mean baseline $\mathrm{FEV}_{1}$ of $85 \%$ of the predicted value). ${ }^{20}$ All groups received rescue $800 \mu \mathrm{g} /$ day of budesonide for 10 days and rescue terbutaline for exacerbations. After 6 months of identical therapy with $800 \mu \mathrm{g} /$ day of budesonide for 1 month and $400 \mu \mathrm{g}$ for 5 months, daily low-dose $(200 \mu \mathrm{g} /$ day $)$ budesonide was associated with $60 \%$ fewer exacerbations and fewer withdrawals due to exacerbations requiring rescue oral corticosteroids than the intermittent group. There was no significant difference in symptom-free days, morning PEF and $\mathrm{FEV}_{1}$, although for several variables the values for the intermittent group were intermediate between that of daily budesonide and cromoglycate. Finally, Martinez and colleagues examined in children with persistent asthma (mean baseline $\mathrm{FEV}_{1}$ of $100 \%$ of the predicted value), daily $100 \mu \mathrm{g}$ of HFA-beclomethasone versus as-needed $100 \mu \mathrm{g}$ of HFA-beclomethasone combined with $200 \mu \mathrm{g}$ salbutamol in a single inhaler. $^{21}$ There was no group difference between daily and as-needed beclomethasone in any outcomes, with the exception of expired nitric oxide, which was significantly lower throughout the study for daily beclomethasone. How does one reconcile these findings?

In an emerging field of a new therapy, the absence of group difference in certain outcomes always raises the issue as to whether the findings are evidence of no effect (real equivalence) or no evidence of effect (lack of power). Giving the size of the confidence intervals, the latter is at play for several outcomes. This issue of statistical power could be overcome by comparing thousands of patients in a new multicentre trial or easier, in a meta-analysis of several randomised controlled trials, such as the one currently in progress with the Cochrane Collaboration. There is also the possibility that patient selection, outcome selection and treatment modalities may affect the findings. Perhaps the most important issue is the accuracy of the phenotype, that is, whether the trials adequately distinguished intermittent from mild persistent asthma. Indeed, one would expect intermittent and daily therapy to work equally well in patients with intermittent asthma, erroneously classified as persistent asthma, because daily therapy would represent overtreatment. The outcomes of interest must be relevant for the level of control, while avoiding the common pitfall of selecting variables with a ceiling effect, that is, variables that are normal or near normal at baseline, such as lung function and rescue $\beta 2$-agonist use, as they require more power to identify as statistically significant differences that may not be clinically important. Selecting exacerbations as an outcome is attractive, as these events may be eventually relevant to most patients, although longer study durations are needed to allow for occurrence of sufficient events in patients with good control at baseline. Could differences in patient phenotypes, baseline asthma control, selection of outcomes and type and duration of interventions account for the apparent discordance in findings?

Clearly, in half of the trials, daily inhaled corticosteroid was superior to intermittent therapy, which in turn was superior to placebo for preventing exacerbations. In these patients, the intermediate efficacy of intermittent therapy is in line with prior observations that, at equal severity, greater compliance to daily controller is associated with better asthma control in patients with persistent asthma. ${ }^{22-25}$ The paediatric study reporting group difference only in expired nitric oxide had selected children with superior lung function, raising the possibility that a substantial proportion has intermittent mild asthma.

What about safety? The search for adverse effects has been minimal so far in adults, but rather extensive in the two paediatric studies. Six-month therapy with high and moderate doses of budesonide was associated with an estimated growth suppression of $2 \mathrm{~cm} /$ year compared with those on cromoglycate. This was followed by normal and even perhaps a catch-up growth in the last 12 months and minor decrease in skin thickness, with no group difference in bone mineral density and intraocular pressure compared with cromoglycate. Although height velocity in the last 12 months was significantly greater by $0.6 \mathrm{~cm}$ in the intermittent group, compared with the daily budesonide groups, there was no significant difference 
in the final height attained, suggesting that the major impact on growth occurred in the initial 6 months. Similarly, in the second paediatric trial, the daily beclomethasone group grew $0.7 \mathrm{~cm}$ less than the intermittently treated group. ${ }^{21}$ The readers are left with the conclusion that one must choose between better control with stunted growth using daily inhaled corticosteroids or more exacerbations with normal growth using intermittent corticosteroids.

However, this paradigm must be rephrased for two reasons. First, because the impact on growth is dose dependent, it is critical to use the smallest effective dose of inhaled corticosteroids and taper it according to control, which was not done in any of the four trials. In the study by Turpeinen and colleagues, the use of high and moderate doses probably resulted in overtreatment for the majority of children enrolled, as most were subsequently well controlled on low-dose budesonide. Second, the growth suppression is drug dependent with group differences of $1.51 \mathrm{~cm} /$ year with $400 \mu \mathrm{g} /$ day of beclomethasone, $1.0 \mathrm{~cm} /$ year with $200 \mu \mathrm{g} /$ day of budesonide and $0.43 \mathrm{~cm} /$ year with $200 \mu \mathrm{g} /$ day of fluticasone. ${ }^{2627}$ The data on ciclesonide has shown no systemic effect to date, including no detectable effect on growth. ${ }^{28}{ }^{29}$ Consequently, there is little reason to accept the known risk of growth suppression associated with beclomethasone or budesonide, when safer inhaled corticosteroids may be used.

How can we move this field forward? Clearly, in view of the expected betweenphysician variability in phenotype ascertainment, we urgently need to validate the criteria recently proposed by several paediatric groups to distinguish intermittent from persistent asthma in preschoolers as well as in school-aged children and adolescents. ${ }^{30-32}$ It appears worthwhile to consider adding an objective measure of lung function (including interrupter technique or oscillometry in preschool-aged children who are too young to undergo spirometry) and inflammatory markers (eg, expired nitric oxide) to improve accuracy and reduce subjectivity in phenotype classifications. ${ }^{33} 34$ With increasing evidence that even with minimal symptoms, people with intermittent asthma display ongoing inflammation, should there be a distinction between mild intermittent and mild persistent asthma? Before adding intermittent therapy as a therapeutic option in our guidelines, we should ensure that we are not causing harm and diligently compare the long-term impact of both strategies on exacerbations, lung growth and function, quality of life and airway remodelling.

In summary, there is insufficient evidence to recommend intermittent therapy in patients with persistent asthma. Half of the published trials testing intermittent versus low-dose continuous inhaled corticosteroids confirmed the superiority of daily lowdose, over intermittent, inhaled corticosteroids, and the latter over placebo; this is entirely consistent with-the better the compliance with daily use of inhaled corticosteroids, the better the asthma control. We should not give up educating our patients about the favourable risk-benefit balance of low-dose inhaled corticosteroids, simply because it is timeconsuming, no more than we should abandon recommending tobacco avoidance, bicycle helmets and car seats. In patients with superior lung function, longer trials are needed before assuming equivalence, as the delay until recurrence of symptoms and exacerbation should be proportional to baseline control and the rapidity of inflammatory build-up. In addition, long-term trials demonstrating the safety of intermittent therapy compared with daily therapy on lung function and airway remodelling must be conducted to ensure that we are not causing harm in these future young adults. One must remember that adverse effects of inhaled corticosteroids are dose dependent and appear to be drug dependent. Until we have more data, it seems that the best approach for children with mild persistent asthma remains inhaled corticosteroids at the lowest effective dose, using the safest molecules. When recommending intermittent therapy, we are telling our patients that asthma is not a chronic disease, only a recurrent one; let us be sure, we have classified the phenotype correctly.

Competing interests $\mathrm{FMD}$ received unrestricted and/or dedicated research funds from Merck Frosst Inc, Merk Canada, Novartis and Nycomed.

Provenance and peer review Commissioned; internally peer reviewed.

Published Online First 13 October 2011

Thorax 2012;67:102-105

doi:10.1136/thoraxjnl-2011-200961

\section{REFERENCES}

1. Guilbert TW, Morgan WJ, Zeiger RS, et al. Long-term inhaled corticosteroids in preschool children at high risk for asthma. New Engl J Med 2006;354:1985-97.

2. Rabe KF, Adachi M, Lai CK, et al. Worldwide severity and control of asthma in children and adults: the global asthma insights and reality surveys. J Allergy Clin Immunol 2004:114:40-7.
3. Halm EA, Mora P, Leventhal H. No symptoms, no asthma: the acute episodic disease belief is associated with poor self-management among inner-city adults with persistent asthma. Chest 2006;129:573-80.

4. Pando S, Lemière C, Beauchesne MF, et al. Suboptimal use of inhaled corticosteroids in children with persistent asthma: inadequate prescription, poor drug adherence, or both? Pharmacotherapy 2010;30:1109-16.

5. Blais L, Kettani FZ, Lemière $\mathrm{C}$, et al. Inhaled corticosteroids vs. leukotriene-receptor antagonists and asthma exacerbations in children. Respir Med 2011;105:846-55.

6. Agertoft L, Pedersen S. Effects of long-term treatment with an inhaled corticosteroid on growth and pulmonary function in asthmatic children. Respir Med 1994:88:373-81.

7. Montuschi P, Pagliari G, Fuso L. Pharmacotherapy of asthma: regular treatment or on demand? Ther Adv Respir Dis 2009:3:175-91.

8. Murray CS. Can inhaled corticosteroids influence the natural history of asthma? Curr Opin Allergy Clin Immunol 2008;8:77-81.

9. Cabana MD, Abu-Isa H, Thyne SM, et al. Specialty differences in prescribing inhaled corticosteroids for children. Clin Pediatr (Phila) 2007:46:698-705.

10. Johnston NW, Johnston SL, Duncan JM, et al. The September epidemic of asthma exacerbations in children: a search for etiology. J Allergy Clin Immunol 2005;115:132-8.

11. O'Byrne PM, Bisgaard H, Godard PP, et al Budesonide/formoterol combination therapy as both maintenance and reliever medication in asthma. $A m \mathrm{~J}$ Respir Crit Care Med 2005;171:129-36.

12. Rabe KF, Atienza T, Magyar $P$, et al. Effect of budesonide in combination with formoterol for reliever therapy in asthma exacerbations: a randomised controlled, double-blind study. Lancet 2006;368:744-53.

13. Bisgaard H, Le Roux $\mathrm{P}$, Bjamer D, et al. Budesonide/ formoterol maintenance plus reliever therapy: a new strategy in pediatric asthma. Chest 2006; 130:1733-43

14. Haahtela $\mathbf{T}$, Tamminen $\mathrm{K}$, Malmberg LP, et al. Formoterol as needed with or without budesonide in patients with intermittent asthma and raised NO levels in exhaled air: A SOMA study. Eur Respir $J$ 2006;28:748-55.

15. Bisgaard H, Hermansen MN, Loland L, et al. Intermittent inhaled corticosteroids in infants with episodic wheezing. New Engl J Med 2006;354:1998-2005.

16. Ducharme FM, Lemire C, Noya FJ, et al. Preemptive use of high-dose fluticasone for virus-induced wheezing in young children. $N$ Engl J Med 2009;360:339-53.

17. Robertson CF, Price D, Henry R, et al. Short-course montelukast for intermittent asthma in children a randomized controlled trial. Am J Respir Crit Care Med 2007;175:323-9.

18. Boushey HA, Sorkness CA, King TS, et al. Daily versus as-needed corticosteroids for mild persistent asthma. New Engl J Med 2005;352:1519-28.

19. Papi A, Canonica GW, Maestrelli P, et al. Rescue use of beclomethasone and albuterol in a single inhaler for mild asthma. $N$ Engl J Med 2007;356:2040-52.

20. Turpeinen M, Nikander K, Pelkonen AS, et al. Daily versus as-needed inhaled corticosteroid for mild persistent asthma (The Helsinki early intervention childhood asthma study). Arch Dis Child 2008;93:654-9

21. Martinez FD, Chinchilli VM, Morgan WJ, et al. Use of beclomethasone dipropionate as rescue treatment for children with mild persistent asthma (TREXA): a randomised, double-blind, placebo-controlled trial. Lancet 2011;377:650-7. 
22. Adams RJ, Fuhlbrigge $A$, Finkelstein $\mathrm{JA}$, et al. Impact of inhaled antiinflammatory therapy on hospitalization and emergency department visits for children with asthma. Pediatrics 2001;107:706-11.

23. Mudd K, Bollinger ME, Hsu VD, et al. Pharmacy fill patterns in young urban children with persistent asthma. J Asthma 2006;43:597-600.

24. Walders N, Kopel SJ, Koinis-Mitchell D, et al. Patterns of quick-relief and long-term controller medication use in pediatric asthma. $J$ Pediatr 2005:146:177-82

25. Suissa S, Ernst P, Kezouh A. Regular use of inhaled corticosteroids and the long term prevention of hospitalisation for asthma. Thorax 2002;57:880-4.

26. Sharek PJ, Bergman DA. The effect of inhaled steroids on the linear growth of children with asthma: a meta-analysis. Pediatrics 2000;106:E8.
27. The Childhood Asthma Management Program Research Group. Long-term effects of budesonide or nedocromil in children with asthma. New Engl J Med 2000;343:1054-63.

28. Von Berg A, Engelstatter R, Minic P, et al. Comparison of Ciclesonide 160ug/d with Budesonide 400ug/d in a Randomised Doubleblind Study in Children with Moderate to Severe Asthma. Pediatr Allergy Immunol 2007:18:391-400.

29. Skoner DP, Maspero J, Banerii D. et al. Assessment of the long-term safety of inhaled ciclesonide on growth in children with asthma. Pediatrics 2008;121 e1-14.

30. Bacharier LB, Boner A, Carlsen $\mathrm{KH}$, et al. Diagnosis and treatment of asthma in childhood: a PRACTALL consensus report. Allergy 2008;63:5-34.
31. Brand PL, Baraldi E, Bisgaard H, et al. Definition, assessment and treatment of wheezing disorders in preschool children: an evidence-based approach. Eur Respir J 2008;32:1096-110.

32. Castro-Rodríguez JA, Holberg CJ, Wright AL, et al. A clinical index to define risk of asthma in young children with recurrent wheezing. Am J Respir Crit Care Med 2000;162:1403-6.

33. Beydon N, Davis SD, Lombardi E, et al. An official American Thoracic Society/European Respiratory Society statement: pulmonary function testing in preschool children. Am J Respir Crit Care Med 2007:175:1304-45

34. Bacharier LB. Does exhaled nitric oxide measurement help distinguish between wheezing phenotypes in preschool children? J Allergy Clin Immunol 2008:121:710-11.

\section{SAVE TIME AND KEEP INFORMED}

\section{Thorax}

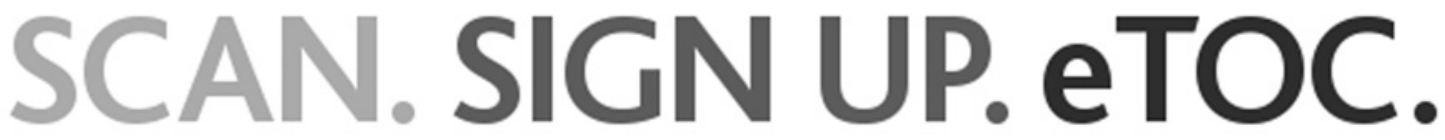

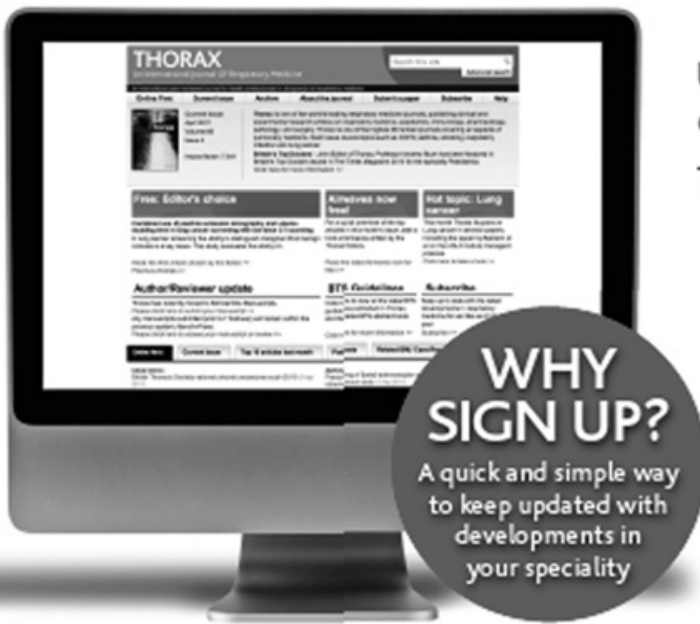

thorax.bmj.com
Utilise our Quick Response code (QR) to sign up for our electronic table of contents (eTOC) alert.

To make this simple you can sign up now via your Smartphone.

\section{FOLLOWTHESE}

\section{THREE EASY STEPS:}

1. Downbad a free $Q R$ reader from your handset's app store

2. Hold your Smartphone over the QR code

3. You will then be fonwarded to the eTOC sign up page

To find out more about $Q R$ codes visit

group.bmj.com/products/journals/qr-codes

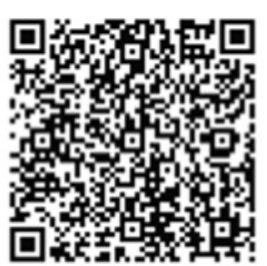

BMJIJournals 